\title{
Development of uveitis during systemic corticosteroid therapy in TINU syndrome
}

\author{
Sebastiano A. G. Lava • Oliver Bucher • \\ Barbara S. Bucher • Giacomo D. Simonetti • \\ Sibylle Tschumi
}

Received: 24 January 2011 / Accepted: 15 February 2011 / Published online: 13 April 2011

(C) IPNA 2011

Sirs,

We read with interest the article of Jahnukainen and colleagues [1] who presented 26 patients with tubulointerstitial nephritis. Twelve patients (46\%) presented bilateral anterior uveitis associated with tubulointerstitial nephritis, also known as tubulointerstitial nephritis and uveitis (TINU) syndrome. One of these 12 patients developed the uveitis prior to the nephrologic disease, in six, uveitis was diagnosed within 2 weeks of the diagnosis of nephritis, and in the remaining five between 3 and 15 months after onset of the nephrologic symptoms. Despite the diagnosis of uveitis, seven patients presented no ocular symptoms.

We followed a 14 year-old female adolescent with unremarkable personal and familial history who complained about fever and headache. The symptomatic therapy did not improve the subjective complaints, and 5 weeks later, leukocyturia, tubular proteinuria, and glucosuria ensued. Clinical examination was normal (body weight $58.5 \mathrm{~kg}$, height $168 \mathrm{~cm}$, blood pressure 118/ $70 \mathrm{mmHg}$, heart rate 76 beats $/ \mathrm{min}$ ); blood analysis revealed a moderate anemia (hemoglobin $107 \mathrm{~g} / \mathrm{L}$ ) together with thrombocytosis (platelets $573 \mathrm{G} / \mathrm{L}$ ) and elevated markers of inflammation (C-reactive protein $87 \mathrm{mg} / \mathrm{L}$, erythrocyte sedimentation rate $76 \mathrm{~mm} / \mathrm{h}$ ).

\footnotetext{
S. A. G. Lava $\cdot$ O. Bucher • B. S. Bucher $\cdot$ G. D. Simonetti $(\bowtie) \cdot$ S. Tschumi

Department of Pediatrics, Pediatric Nephrology Unit, Inselspital, 3010 Bern, Switzerland

e-mail: Giacomo.simonetti@insel.ch
}

Acute renal failure (creatinine up to $141 \mu \mathrm{mol} / \mathrm{L}$ ) and persistent signs of tubular damage induced us to perform a renal biopsy, which highlighted severe acute tubulointerstitial nephritis. At that time, ophthalmological examination was normal, and the etiology of interstitial nephritis was unknown. Therapy with systemic corticosteroids was started: methylprednisolone endovenous $10 \mathrm{mg} / \mathrm{kg}$ for 3 days, followed by oral prednisolone $80 \mathrm{mg}$ daily, which was tapered in the following 4 months. Nephritis rapidly improved (creatinine and urea decreased to normal values; glucosuria and tubular proteinuria disappeared, Fig. 1). However, 2 months later, still under high-dose systemic corticosteroids $(0.5 \mathrm{mg} / \mathrm{kg} / \mathrm{d})$, the patient presented with pain and redness of both eyes. Ophthalmological examination revealed anterior bilateral uveitis, which was successfully treated with topical corticosteroids.

TINU syndrome was first described 1975 by Dobrin and colleagues [2]. Uveitis usually follows nephritis, with a delay of 3 months on average [3]. In our case, uveitis ensued when the patient was still under systemic high-dose corticosteroids (Fig. 1), as has been already described in the literature [4]. The very interesting report of Jahnukainen et al. [1] does not indicate whether uveitis developed during therapy with high-dose systemic corticosteroids.

TINU syndrome is a rare diagnosis, which should be suspected when a young patient presents with interstitial nephritis. As uveitis may rarely also occur during high-dose treatment with systemic corticosteroids and can be asymptomatic, regular ophthalmological follow-up is warranted in patients with tubulointerstitial nephritis. 


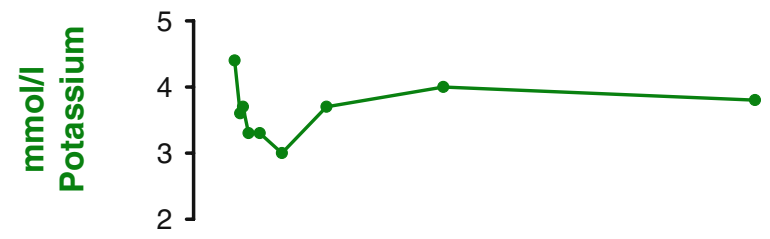

\section{References}

1. Jahnukainen T, Ala-Houhala M, Karikoski R, Kataja J, Saarela V, Nuutinen M (2011) Clinical outcome and occurrence of uveitis in children with idiopathic tubulointerstitial nephritis. Pediatr Nephrol 26:291-299

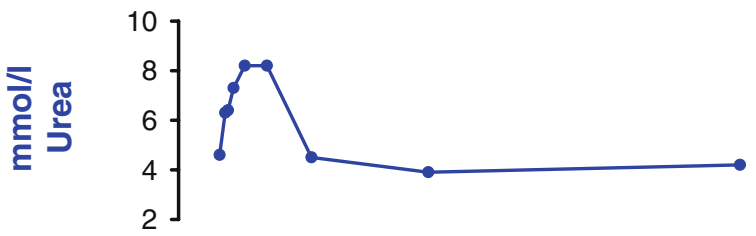

2. Dobrin RS, Vernier RL, Fish AL (1975) Acute eosinophilic interstitial nephritis and renal failure with bone marrow-lymph node granulomas and anterior uveitis. A new syndrome. Am J Med 59:325-333

3. Mandeville JT, Levinson RD, Holland GN (2001) The tubulointerstitial nephritis and uveitis syndrome. Surv Ophthalmol 46:195-208

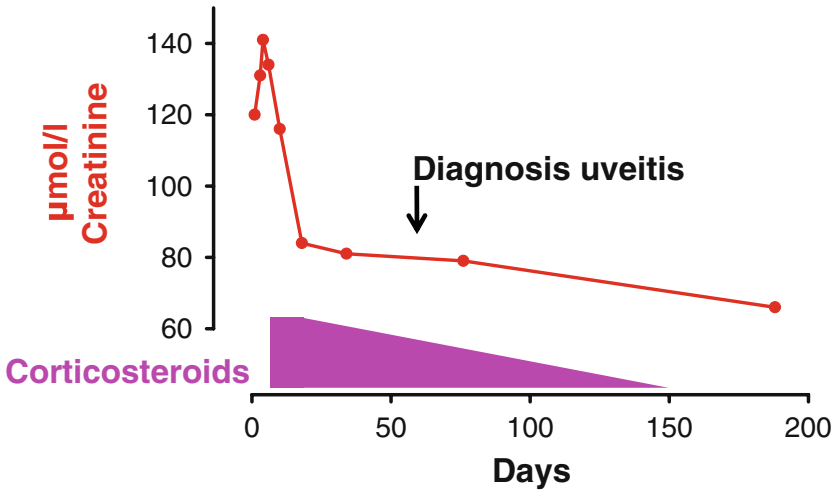

4. Grefer J, Santer R, Ankermann T, Faul S, Nölle B, Eggert P (1999) Tubulointerstitial nephritis and uveitis in association with epsteinbarr virus infection. Pediatr Nephrol 13:336-339

Fig. 1 A 14-year-old female adolescent developed bilateral anterior uveitis during high-dose corticosteroid therapy 2 months after the diagnosis of tubulointerstitial nephritis (arrow), allowing the final diagnosis of tubulointerstitial nephritis and uveitis (TINU) syndrome. Systemic corticosteroid dose is indicated in the text 